\title{
Importancia de los territorios rurales en el proceso de reestructuración territorial: el caso de la región metropolitana de la ciudad de Puebla
}

\section{Importance of the rural territories in the process of territorial restructuration: the case of the metropolitan region of the city of Puebla}

\author{
Héctor Bernal-Mendoza* \\ JaVier RAMírez-JuÁrez ${ }^{* *}$ \\ Néstor Estrella-Chulím** \\ Ricardo PÉREZ-Avilés* \\ Jorge Luis MoretT-SÁNCHEZ ${ }^{* * *}$
}

\begin{abstract}
We expose the main contradictions between the process of territorial ordering and the concept of development for the metropolitan region of the city of Puebla; likewise, we emphasize the importance of rural territories, their actors and their culture in this process. In this framework, and on the basis of the territorial approach of development, in the multifunctional character of land and water and the theory of social capital, the importance of the reorganization and characterization of the space and their actors become evident for a more sustainable planning model and development with territorial approach.
\end{abstract}

Keywords: territorial restructuration, territorial ordering, Puebla, ejido, rural.

\begin{abstract}
Resumen
Se exponen las principales contradicciones entre el proceso de ordenamiento territorial y el concepto de desarrollo para la región metropolitana de la ciudad de Puebla. Asimismo se enfatiza la importancia de los territorios rurales, sus actores y su cultura en este proceso. En este marco, y con base en el enfoque territorial del desarrollo, en el carácter multifuncional de la tierra y el agua y la teoría del capital social, se evidencia la importancia de la reorganización y caracterización del espacio y sus actores para un modelo más sustentable de planeación y desarrollo con enfoque territorial.
\end{abstract}

Palabras clave: reestructuración territorial, ordenamiento territorial, Puebla, ejido, rural.

\footnotetext{
* Benemérita Universidad Autónoma de Puebla, México. Correos-e: hector.bernal@fiquim.buap.mx y cs000305@siu.buap.mx.

** Colegio de Postgraduados, Campus Puebla. Correos-e: jramirez@colpos.mx y nestrela@colpos.mx.

*** Universidad Autónoma Chapingo. Correo-e: jlmorett@correo.chapingo.mx
} 


\section{Introducción}

En la actualidad, con el crecimiento desordenado y acelerado de las ciudades latinoamericanas sobre sus periferias, es frecuente escuchar a las autoridades, en sus diferentes niveles de gobierno, hablar de políticas complejas, programas y proyectos - paralelos y necesarios, sin lugar a dudas- sobre cómo ordenar dichos procesos de expansión urbana. Ciertamente no es una cosa fácil, aun cuando la preocupación y las acciones de los gobiernos sean genuinas y honestas. Pero es aún más complicado cuando existe la posibilidad de que dichas políticas vayan en un sentido diferente de la idea que tenemos de ordenamiento territorial.

En este proceso, tan ligado a la mundialización de la economía y a la concentración del capital trasnacional, ha sido primero lenta y después más acelerada la exclusión de diversos territorios y actores regionales, que si bien en la actualidad no son mayoritarios, siguen jugando un papel importante en el equilibrio y sostenibilidad del sistema regional.

El presente artículo deriva de la investigación para obtener el grado de doctor en ciencias en el programa Estrategias para el Desarrollo Agrícola Regional, del Colegio de Postgraduados en ciencias agrícolas, Campus Puebla, denominada "Propiedad social y desarrollo: el papel territorial de los actores sociales en la Región Metropolitana de Puebla”. Dicha investigación se llevó a cabo durante los años 2004-2007, en una de las cuatro regiones conurbadas más complejas de México: la de la ciudad de Puebla, un área que en el año 2005 contaba con 2'070,547 pobladores distribuidos en 12 municipios conurbados.

Los resultados de la investigación muestran que la tendencia en la región favorece un modelo de desarrollo basado en la industria y el crecimiento inmobiliario, cuyos efectos inmediatos son, entre otros, la pérdida de tierra y recursos naturales de los ejidos, la pérdida de oportunidad de aprovechar sus ya pocas reservas territoriales, agrícolas y ecológicas, la contaminación de suelo, agua y aire y, sobre todo, la pérdida de la cultura regional.

Dichos resultados nos alertan para reflexionar acerca de cómo han evolucionado nuestras urbes, y sobre la posibilidad que aún tenemos en muchos casos de corregir el camino y revalorar nuestro mundo rural, cada vez más en peligro de desaparecer. 


\section{Análisis teórico, conceptual y empírico del problema}

\subsection{Contradicciones entre reestructuración y ordenamiento territorial en la región metropolitana de Puebla}

El concepto ordenamiento territorial implica, de acuerdo con Gross, "la búsqueda de la disposición correcta, equilibrada y armónica de la interacción de los componentes del territorio. Entre ellos, la forma que adquiere el sistema de asentamientos humanos, dado su carácter complementario e indisoluble en la formación del territorio" (1998: 2).

La Carta Europea de Ordenación del Territorio define ordenamiento territorial como la "expresión espacial de la políticas económica, social, cultural y ecológica de toda la sociedad, lo cual es útil porque ubica al concepto en el contexto preciso de las voluntades explícitas de un grupo social, generalmente plasmadas en leyes y ordenamientos" (Comité de Ministros, 1984: 4).

Para Mac Donald y Simioni (1999), este tipo de ordenamiento se entiende como un proceso de organización del territorio en sus aspectos sociales y económicos, lo cual permite la incorporación del mayor número de componentes endógenos en forma consensuada y que haga compatibles los componentes ambientales del territorio, las aspiraciones sociales y mantener niveles de productividad crecientes en las actividades económicas. Se trata del proceso mediante el cual se distribuye la actividad humana de forma óptima y sustentable en el territorio.

Para la Ley Cántabra en materia de ordenamiento del territorio se trata de "el conjunto de criterios, normas y planes que regulan las actividades y asentamientos sobre el territorio con el fin de conseguir una adecuada relación entre el territorio, población, actividades, servicios e infraestructura" (citado en Gómez, 2002: 30).

A partir de tales enfoques, entendemos que una estrategia de ordenamiento territorial (от) debe detectar las diversas problemáticas regionales urbanas y locales, por medio de diagnósticos, y formulando proyectos y programas operativos sobre el manejo de los asentamientos humanos, los recursos naturales, la población, la producción, el equipamiento e infraestructura y la localización de las inversiones, etc., las cuales sin duda son medidas fundamentales para el desarrollo sostenible de una región.

Sin embargo, estas medidas sólo pueden derivar de un proceso real de toma de decisiones, que implica tomar en cuenta a los actores involucrados, permitiendo una verdadera distribución del crecimiento económico de acuerdo con la integridad y potencialidad del territorio, que incluye el manejo equitativo y eficiente del subsistema natural (el total de los recur- 
sos naturales), del subsistema construido (la infraestructura y en general toda obra humana) y del subsistema social (el capital humano y social).

La ciudad de Puebla y su región metropolitana, la cuarta concentración demográfica más importante del país, se compone de 31 municipios de los estados de Puebla y Tlaxcala (12 y 19, respectivamente), con una superficie de $1,867.7 \mathrm{~km}^{2}$ y una población estimada en el año 2000 en 2’121,000 habitantes, población casi igual en 2005 sólo de los 12 municipios conurbados de Puebla (mapas I y II).

En la región de estudio, el proceso que aquí llamamos reestructuración territorial (RT) comienza a tomar forma para su análisis y comprensión, a partir de la decadencia de las empresas textiles de Puebla y Tlaxcala durante los ańos sesenta y setenta, cuando algunos sectores empresariales, como los de origen libanés que llegaron durante la segunda Guerra Mundial y dedicaron sus capitales a dicha industria, deciden diversificarse en nuevas actividades, como la industria de la construcción e inmobiliaria.

\section{Mapa I \\ Delimitación municipal de la región metropolitana de Puebla}

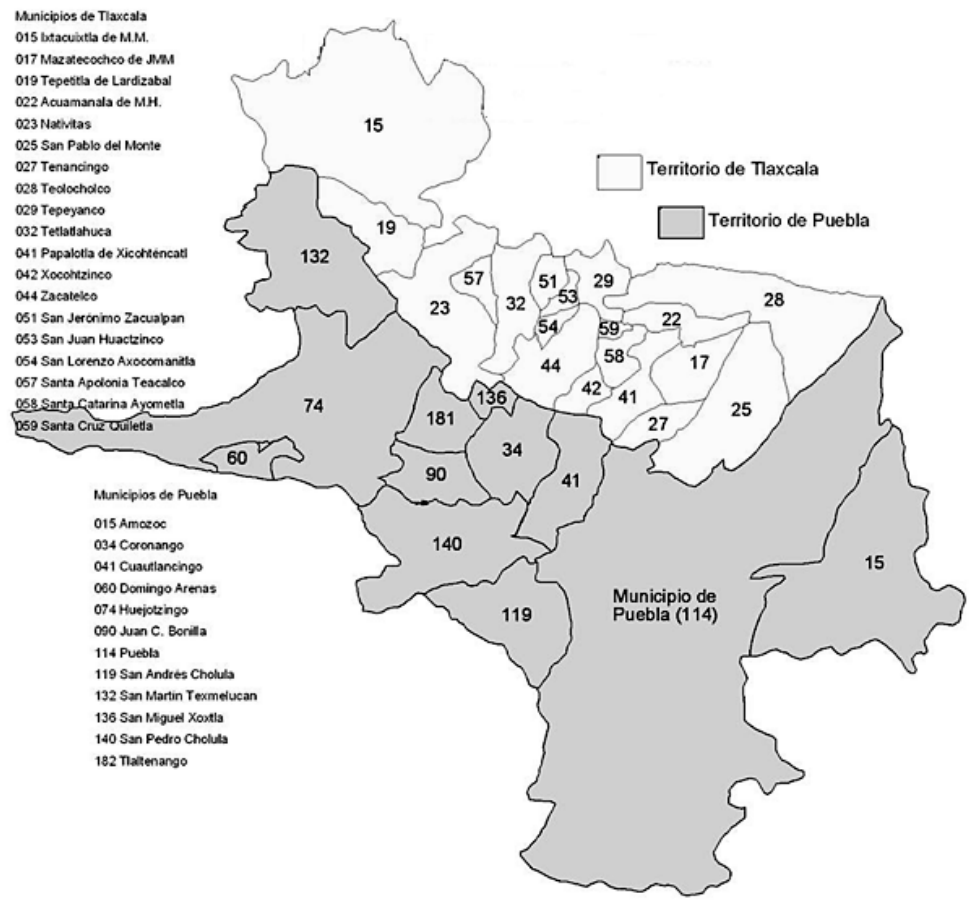

Fuente: Elaboración propia con base en INEGI (2004). 


\section{Mapa II \\ Espectro urbano de la región metropolitana de Puebla}

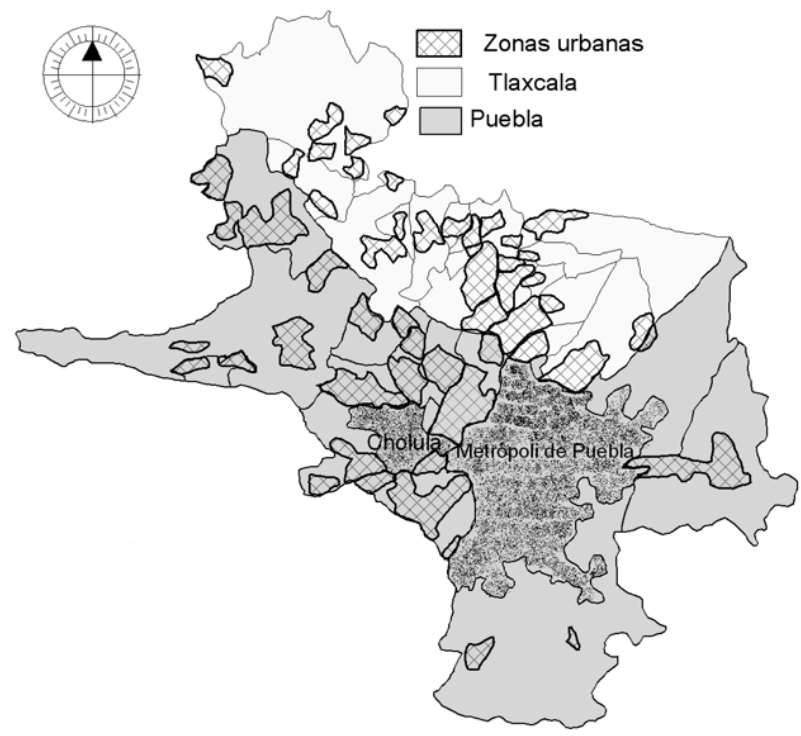

Fuente: INEGI (2004).

$\mathrm{Al}$ mismo tiempo, en estas décadas se introduce nueva e importante infraestructura urbana, como la autopista México-Veracruz en 1962, se fortalecen las líneas del ferrocarril, se construyen gasoductos, líneas de alta tensión, etc., y comienza la venta de terrenos ejidales expropiados, con el objetivo de diversificar la industria regional; así llegan empresas importantes como la automotriz Volkswagen en Cuautlancingo y la siderúrgica Hojalata y Láminas, s.A. (HYLSA) en San Miguel Xoxtla, las cuales ya en los años setenta reunían $24 \%$ del valor de la producción del estado de Puebla y $69 \%$ de los empleos que en conjunto ofrecían las empresas textiles.

Estos procesos socioeconómicos se acompańaron de acciones de especulación sobre superficies susceptibles de construir unidades habitacionales o industrias, así como de una competencia interterritorial entre municipios, e incluso interestatales, para atraer a las empresas que buscaban asentarse en la región, las cuales aprovecharon las facilidades fiscales y legales que les ofrecieron: leyes de exención de impuestos locales, así como facilidades para su instalación y/o ampliación. ${ }^{1}$

\footnotetext{
${ }^{1}$ Las leyes de fomento industrial de 1963 y 1968 ampliaron las facilidades que otorgaban sus predecesoras, otorgando exoneraciones fiscales de $50 \%$ a las empresas que incrementaran su capital entre 60 y $70 \%$ o su número de empleados entre 40 y 50\% (Melé, 1994: 89-90), en tanto que la
} 
Durante esta fase y hasta 1991, la agricultura y los territorios rurales habían representado una actividad económica importante, con una superficie aproximada de 118,013 ha que representaba $63 \%$ del total regional (186,778 ha), tomando en cuenta las unidades de producción privadas y ejidales. En la actualidad, es evidente la caída de la producción agrícola en la región, ya que los datos para 2003 (Sagarpa, 2005) muestran que para el caso de Puebla (cuadro 1), la superficie sembrada en ese año en los municipios incluidos en la región de estudio fue de 47,921 ha, que equivale a $37.1 \%$ de la superficie de estos 12 municipios (128,891 ha), y el valor de la producción fue de casi 314 millones de pesos, 5\% del valor total de la producción agrícola del estado, lo cual es poco significativo.

La orientación de las acciones de los gobiernos federal y estatal durante la década de los setenta, parecieron reconsiderar, una vez más, la vieja idea de la importancia geoestratégica de la región metropolitana de Puebla entre el Golfo, la ciudad de México, el sur y el océano Pacífico. Pero incluso desde esta perspectiva, el espacio rural (particularmente la agricultura) jugaba un papel importante, lo cual se puede ver, en parte, en el énfasis que el modelo de desarrollo estabilizador le daba y que fue impulsado por el presidente Luis Echeverría, el cual concedía cierta importancia a las necesidades regionales de abastecimiento de alimentos y materias primas, introducción de nueva tecnología y organización para la producción de los campesinos de la región. ${ }^{2}$

En esta nueva etapa de expansión urbana de la ciudad de Puebla, se utilizó una estrategia de incremento de los factores de localización regionales, instalando industrias fuera de los límites de la ciudad a costa de expropiar territorios rurales (básicamente ejidales), así como de facilidades fiscales y legales con fondos públicos, para impulsar infraestructura netamente urbana (autopista, carreteras, transporte, líneas eléctricas, gasoductos, áreas residenciales, etc.) con la finalidad de cambiar la estructura y la función económica de la región a un nuevo tejido industrial. Dicha estrategia se planeó al menos en tres vertientes o ejes: la carretera PueblaTlaxcala, la carretera México-Puebla (tramo San Martín TexmelucanPuebla) y los espacios intersticiales entre éstos (mapa III).

Ley de Fomento Industrial y de Promoción de Conjuntos, Parques, Corredores y Ciudades Industriales del Estado de Puebla (1972) otorgó exenciones fiscales por 10 años a empresas nuevas.

${ }^{2}$ En este contexto, a finales de la década de los sesenta se impulsó uno de los programas de desarrollo agrícola regional más importantes en la historia de México, el llamado Plan Puebla, en principio enfocado a apoyar a productores minifundistas -principalmente de maíz y otros cultivos básicos- de 32 municipios de la región occidental del estado de Puebla, beneficiando ya en 1971 a cerca de 267,000 personas (CIMMYT, 1974: 6) y teniendo entre sus logros más notables el incremento de la producción de maíz hasta en $300 \%$ y el volumen de créditos otorgados y recuperados, de 6,000 dólares en 1968 a 447,712.88 dólares en 1970 (Jiménez, 1974: 18). 


\section{Cuadro 1}

Agricultura en los 12 municipios de Puebla, 2003

\begin{tabular}{lrr}
\hline \multicolumn{1}{c}{ Municipio } & $\begin{array}{c}\text { Sup. sembrada } \\
\text { ( } \mathrm{ha} \text { ) }\end{array}$ & $\begin{array}{c}\text { Valor de la prod. } \\
\text { (miles de pesos) }\end{array}$ \\
\hline Estado de Puebla & $843,629.81$ & $6257,752.51$ \\
Amozoc & 6,521 & $24,713.35$ \\
Coronango & 2,807 & $21,721.7$ \\
Cuautlancingo & 2,944 & $26,551.9$ \\
Dmgo. Arenas & 1,066 & $6,411.4$ \\
Huejotzingo & 5,677 & $52,875.08$ \\
Juan C. Bonilla & 2,471 & $15,913.5$ \\
Puebla & 10,878 & $24,493.65$ \\
S.A. Cholula & 1,710 & $18,185.29$ \\
S.M. Texmelucan & 5,660 & $66,143.03$ \\
San Miguel Xoxtla & 547 & $4,155.62$ \\
S.P. Cholula & 5,064 & $31,479.44$ \\
Tlaltenango & 2,576 & $21,334.4$ \\
Total: 12 & 47,921 & $313,978.36$ \\
\hline
\end{tabular}

Fuente: Sagarpa (2005).

Nota: Incluye cultivos cíclicos y perennes, riego y temporal.

La construcción de los corredores industriales son elementos empíricos significativos que permiten distinguir en la región el inicio de las contradicciones entre lo urbano y lo rural. Con esta contradicción, comienza una competencia desigual entre lo urbano (industrias, unidades habitacionales, vialidades, etc.) y lo rural (agricultura, zonas de reserva ecológica, etc.), pues si bien estas acciones incrementaron la plusvalía regional al introducir infraestructura con inversión federal para recibir a las empresas que se estaban descentralizando de la ciudad de México, también es cierto que en esta zona se encontraban las mejores tierras de cultivo del estado, y que existía un modo de vida ligado a las tradiciones que las industrias capitalizaron para adaptarlas a la disciplina laboral.

A partir de los años setenta, con la Ley de Fomento Industrial y de Promoción de Conjuntos, Parques, Corredores y Ciudades Industriales del Estado de Puebla de 1972, y las normativas que le han seguido, comienza un cambio de interpretación de los principios locales y nacionales establecidos para descentralizar la industria de los grandes centros urbanos que preveían problemas relacionados con la contaminación, el ordenamiento urbano y la desconcentración industrial, que en la práctica se trataba de una lógica de concentración de una parte de desarrollo en las zonas de fuerte densidad demográfica. 


\section{Mapa III \\ Corredores y zonas industriales en la RMP}

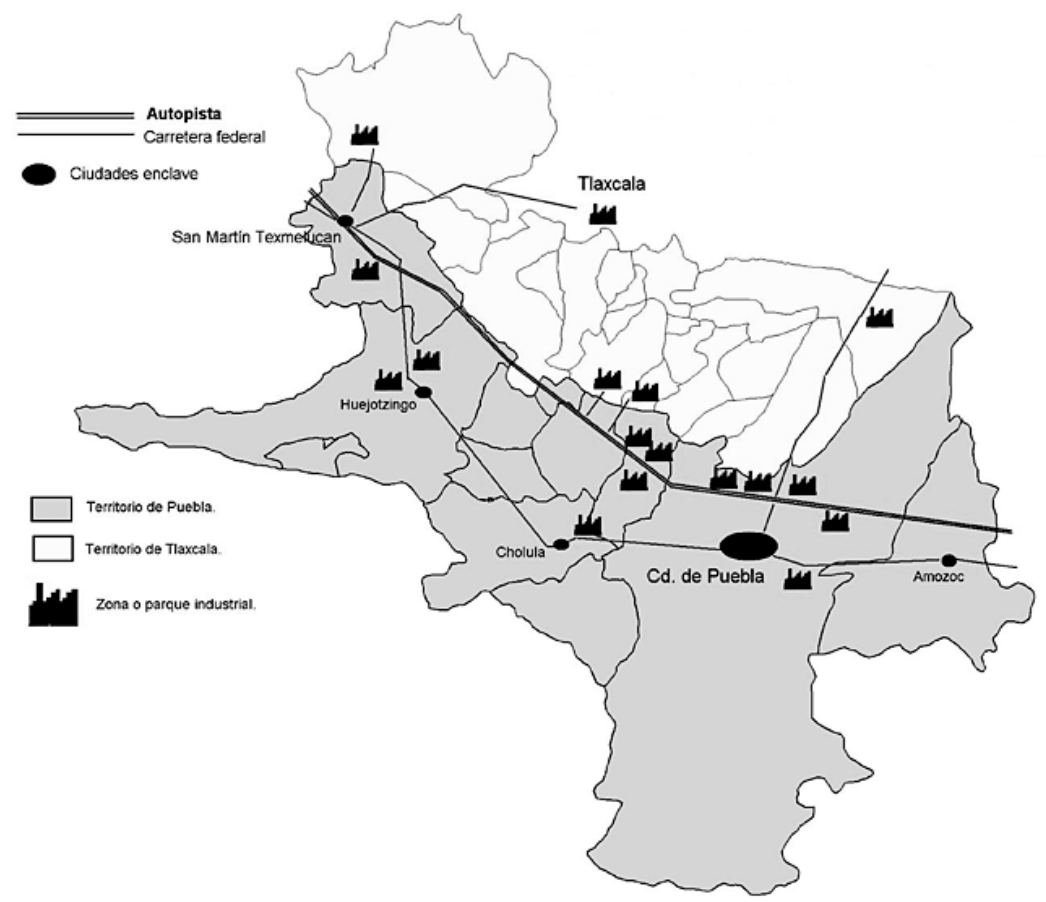

Fuente: Elaboración propia con base en INEgi (2004) y H. Ayuntamiento de Puebla (1999).

En este proceso de industrialización, ya descrito por algunos autores (Melé, 1994: 92; Barbosa, 1993; Flores, 2002: 212-217), hay que señalar con insistencia que parte de la evidencia para afirmar que en la región no ha existido un proceso consistente de от, es que a pesar de que había instrumentos normativos importantes, como la Ley de Subsidio a las Industrias Nuevas en el Estado (1943), el Plan Regulador de la Ciudad de Puebla (1952), la Ley de Fomento Industrial (1957) y el Plan de Mejoramiento Urbano (1959), los cuales consideraban aspectos como segregación industrial en locales independientes (industrias separadas de otros espacios como los artesanales y habitacionales), zonificaciones, en un intento de gestionar la localización y regulación de los diferentes elementos urbanos (áreas industriales separadas de la ciudad por áreas verdes, zonas habitacionales, de recreación, etc.), éstos poco a poco fueron modificados o eliminados convencionalmente bajo la lógica unívoca de que los intereses del mercado debían estar por encima de todo.

Algo similar sucedió con la Ley para el Desarrollo Urbano y los Asentamientos Humanos del estado de Tlaxcala (1978), el Plan de Desarrollo 
Urbano del estado de Tlaxcala (1979), así como los planes regionales, que fueron espejo del enfoque dado en la ciudad de Puebla.

En 1994, 15 de las 24 empresas más importantes del estado de Puebla se encontraban en estos ejes de crecimiento industrial (Melé, 1994: 84), algunas de las cuales incluso desde el principio tejieron sus propias áreas de influencia laboral, de empresas subsidiarias, de transporte, entre otras. ${ }^{3}$

A partir de este punto, y muchas veces al amparo de procesos complicados -e incluso fuera de la ley o vendiendo los lotes a precios simbólicos-, los parques industriales se multiplicaron en la región, particularmente durante los sexenios de los gobernadores Mariano Piña Olaya y Manuel Bartlett Díaz. Como en ocasiones anteriores, en casi todos los casos fueron los ejidos los que aportaron la superficie necesaria. En este mismo sentido, el estado de Tlaxcala encaminó sus acciones de concentración industrial sumándose a las de Puebla (Melé, 1994: 99) sobre la carretera Puebla-Tlaxcala (Panzacola, Xicotzingo y Zacatelco), además de instalar el corredor industrial Malinche entre Santa Ana Chiautempan y Puebla y el de Ixtacuixtla en las cercanías de San Martín Texmelucan (mapa III).

Así, se gestaba un proceso regional no de ordenamiento urbano e industrial, mucho menos territorial, sino más bien, un proceso de reestructuración del espacio a costa de los territorios rurales. Es este proceso de RT, es la metrópoli poblana la que define la construcción contemporánea. ${ }^{4}$

Podemos afirmar, entonces, que la región metropolitana de Puebla (RMP), como se aprecia actualmente, se empieza a definir con medidas -algunas de ellas poco democráticas- que tuvieron como objetivo controlar este reacomodo territorial de la urbe por encima de sus territorios rurales.

Aunque el proceso comenzó en 1962, cuando se suprimieron e incorporaron al municipio de Puebla varios municipios circundantes (San Jerónimo Caleras, San Felipe Hueyotlipan, San Miguel Canoa, La Resurrección y Totimehuacán), ${ }^{5}$ lo que casi triplicó su superficie municipal, de 182 a 524 km² (Melé, 1994: 103; H. Ayuntamiento de Puebla, 1999:

${ }^{3}$ Como la planta de metanol de Petróleos Mexicanos en San Martín Texmelucan (1962), la armadora automotriz de Volkswagen (1965) y la Siderúrgica HYLSA (en 1967), entre otras, casi todas bajo amplias expropiaciones de terrenos de ejidos como Cuautlancingo, San Francisco Ocotlán, Xoxtla y otros más.

${ }^{4}$ Aunque no hay consenso muy claro al respecto, es común definir el concepto de metrópoli con base en la noción de gravitación respecto de un principal centro de actividad y de gobierno, con las debidas limitantes que ha establecido el fenómeno de la globalización. De acuerdo con algunos autores citados por Rodríguez y Oviedo (2001), el término metrópolis originalmente significaba ciudad madre o principal centro de gravedad, y fue inventado para designar una realidad urbana que no podía ser entendida como una ciudad autocontenida y con una estructura fija, sino como un mosaico de territorios donde convergen la ciudad y el medio rural.

${ }^{5}$ Aunque ya existía un antecedente de este tipo de acciones en 1943, cuando se suprimieron, incorporaron al de Puebla los municipios de La Libertad y Xochimehuacán. 
5) y en consecuencia aumentó su recaudación fiscal, en realidad el proceso de expansión de la ciudad se manifestó durante los años setenta, cuando aparecen numerosas colonias y unidades habitacionales al oeste y sur de la ciudad, en dirección de Cholula, Cuautlancingo y Atlixco, para después extenderse a otras partes de la periferia de la ciudad, tendencia que persiste hasta ahora, a pesar de que varias legislaciones, como el Plan Director Urbano del estado de Puebla (1980), reconocían la importancia de establecer y respetar límites y reservas. ${ }^{6}$

Otro aspecto que caracteriza el nuevo rumbo de la metrópoli es la especulación por la tierra, notable a partir de los ańos sesenta. De acuerdo con los datos que se tenían en 1994, después de 1960 y hasta mediados de los setenta, $83 \%$ de los fraccionamientos fueron aprobados, acciones que se caracterizaron por infligir constantemente las normas de uso del suelo que habían sido aprobadas (Melé, 1994: 123), como los límites de crecimiento de la ciudad, reservas de uso agrícola o natural, procedimientos para la construcción de viviendas, etc. Tal fue el caso de todos los fraccionamientos al suroeste de la ciudad entre el río Atoyac y los límites del municipio de Puebla con el de Cholula, así como con la salida a Atlixco (reservados para uso exclusivo de la agricultura). ${ }^{7}$

De acuerdo con Melé (1994: 128), el Programa de Desarrollo Urbano de la Ciudad de Puebla (1991) apuntó que de 1980 a 1990, más de la mitad del crecimiento urbano de la ciudad $(21.7 \mathrm{~km}$, en su mayoría destinado para viviendas) no respetó el uso del suelo establecido por el propio programa, aun cuando fueron los propios funcionarios de las instituciones de gobierno los encargados de maniobrar políticamente -y no en lo administrativo- para que esto fuera posible, utilizando los medios y las instituciones legales a su alcance, como la Secretaría de la Reforma Agraria (SRA) y la Comisión para la Regularización de la Tenencia de la Tierra (Corett), en coordinación con instancias políticas corporativas ligadas al Partido Revolucionario Institucional (PRI), para lograr que tierras -sobre todo ejidales-se incorporaran a esto que llamamos reestructuración territorial.

\footnotetext{
${ }^{6}$ Esto se refiere a que en las zonas que había entre el río Atoyac y los límites municipales debían constituirse reservas agrícolas libres de otro tipo de infraestructura, lo cual no se respetó y se ha saturado de unidades habitacionales y de vialidades.

${ }^{7}$ Vélez (2004) menciona que salvo por las 58 unidades habitacionales construidas entre 1972 y 1999, el crecimiento físico de la ciudad se caracteriza por ser horizontal, de baja densidad constructiva y poblacional sobre reservas territoriales o en áreas alejadas de los bordes más compactos de la mancha urbana que han propiciado una ocupación desordenada del territorio municipal, y se constituyeron en un incentivo para especular con el suelo, cuyo resultado ha sido el desarrollo de vacíos urbanos de grandes proporciones que, hasta 1999, se tenían identificadas en aproximadamente 4,000 ha subutilizadas por falta de infraestructura básica, conectividad e incluso inseguridad jurídica, lo que representa graves problemas y deficiencias en el crecimiento físico de la ciudad.
} 
De esta manera, el espacio, como se ha visto en la historia reciente de la RMP, se ha venido transformando de una relación de dominación de lo urbano sobre lo rural, a una relación de marginación y de exclusión sobre el segundo. Visto de manera particular, a partir de fines de los años sesenta y principios de los setenta hasta ahora, ha existido un cambio notable en el rumbo de las políticas urbanas regionales, una especie de ruptura $^{8}$ con la idea original de ordenamiento territorial, puesto que de una relación de dominación ha pasado a una relación de exclusión, en un sistema urbano que considera que ya no necesita a los territorios rurales porque son poco competitivos.

\subsection{La importancia del enfoque territorial del desarrollo y el carácter multifuncional de la agricultura y la tierra para una nueva visión de las relaciones urbano-rurales}

En el orden de ideas expuesto, podemos decir que en el enfoque que guía a la RT no se reconoce en los hechos el vínculo de poder entre los agentes responsables de la expansión urbana (empresarios, agentes inmobiliarios, etc.) con los supuestos planificadores (políticos, legisladores, etc.), por lo que en la práctica naturalmente surgen constantes contradicciones entre las políticas, los programas y los planes de supuesto ordenamiento territorial y las verdaderas intenciones de reestructurar el espacio.

En este sentido, algunos autores como Harvey (1996, citado por Caravaca, 1998) han señalado que parte de la problemática espaciotiempo se debe a que estos procesos de innovación provocan una estampida de cambios - no sólo de productos, procesos, modos de trabajo y estilos de vida, sino también espaciales-, que desintegran formas territoriales para crear otras nuevas, radicalizan la organización del espacio, fragmentan y polarizan a la sociedad. Porque ante una propuesta artificial de un espacio de redes y flujos, persiste otro espacio más real, aquél donde se desarrolla la vida cotidiana, concreta y no virtual, unida inseparablemente a la cultura y a la historia de la región.

Este tipo de espacio, que algunos autores denominan espacio de lugares (como Caravaca, 1998), ${ }^{9}$ existe dentro del propio espacio urbano de

\footnotetext{
${ }^{8}$ Algo parecido a lo que Milton Santos (1996: 80) llama periodización, referente a un cambio de régimen donde las variables funcionan armónicamente, o de ruptura, donde las variables dejan de funcionar y hay crisis en la cual la organización permite el funcionamiento hasta nuevas condiciones. Pero en este caso partimos de la tesis de que ha existido una intencionada reestructuración y refuncionalización, aun sin estar seguros de que las variables vigentes de ordenamiento territorial a escala nacional ya no fueran de utilidad; sin embargo, es relevante seńalarlo, como lo hace el autor, puesto que nos permite empirizar el tiempo y el espacio.

9 Lo que Milton Santos llama también espacios banales o "lo local", que está en contradicción con "lo global"; es decir, "el espacio de todos" contrapuesto "al espacio al servicios de unos pocos" (1996: 76).
} 
la metrópoli, pero también en los propios territorios que persisten como rurales en la RMP, que son básicamente ejidales.

El problema consiste, entonces, en que este tipo de espacio de flujos que se pretende construir tiende a concentrar cada vez más la riqueza y el poder regionales, pues localiza y hegemoniza las funciones de dirección, gestión, control, producción de conocimientos e innovación, constituyéndose en centros rectores del modelo espacial, pero al hacerlo va desconectando aquellos territorios no competitivos, excluyéndolos del sistema dominante, ya que estos nuevos modelos territoriales sólo articulan e integran aquellos territorios que necesita porque son funcionales y rentables para la acumulación de capital, excluyendo a los demás territorios y, por ende, a sus pobladores, lo cual origina una contradicción, un conflicto, ${ }^{10} \mathrm{o}$ dejándolos como reserva de mano de obra o depósito de desechos, lo cual es opuesto a los planteamientos del desarrollo sostenible y equilibrado de los discursos oficiales, que se basan en la solidaridad y ciertos valores morales y éticos (equilibrio en la distribución de la riqueza). Esto termina invariablemente por manifestarse en desigualdades, entre riqueza y pobreza.

Este proceso lo sustenta bastante bien Hiernaux-Nicolás cuando dice que "las nuevas tendencias de la economía capitalista encuentran su base territorial en la recomposición de la esfera regional, que articulada con nodos urbanos de alta integración, constituyen el nuevo fundamento de la dinámica territorial" (1990: 154). Considera, por tanto, que en el contexto de la revolución tecnológica la distancia ha dejado de ser una variable central del análisis espacial, y la flexibilidad del trabajo ha pasado a ocupar un lugar relevante en nuevas formas flexibles de organización laboral (permitidas por elementos tecnológicos como la microelectrónica), nuevos ajustes en las relaciones salariales y sindicales, en los diferentes subsistemas del desarrollo capitalista neoliberal (que él denomina vías), así en como la formación de bloques económicos que implican la homogeneización de naciones y el retiro del Estado en su responsabilidad sobre la organización territorial, los cuales son factores contextuales de un nuevo paradigma regional. ${ }^{11}$

\footnotetext{
${ }^{10}$ Que se manifiesta en la construcción de carreteras como la de Tepeaca -proyecto Millenium-, Nopalucan y Lara Grajales, en el avance industrial (instalación de un gasoducto que afecta a campesinos de Axocopan y San Juan Amecac, Atlixco), en el crecimiento urbano sobre reservas ecológicas o agrícolas (Toltepec, Cholula -casas sobre el Cerro de Zapotecas-, Puebla -centro comercial en un terreno de 100 ha de Cementos Mexicanos-, Huixcolotla -central de abasto en Cuapiaxtla-, etc.), entre otros muchos que están surgiendo mientras escribimos estas líneas.

${ }^{11}$ Se pueden citar en este contexto, y en la pretensión de reformas federales a las leyes laborales, los conflictos que enfrentan industrias regionales importantes como la destiladora Bacardí, la automotriz Volkswagen y la textil y maquiladora Qualytel, que buscan reestructurar derechos laborales ganados históricamente por sus trabajadores.
} 
Y es en el contexto que se ha analizado, que nuevas propuestas teóricas y metodológicas surgen como posibilidades interpretativas y operativas para corregir la problemática.

Estas propuestas plantean que en el intento de síntesis y comprensión es donde el concepto de territorio juega un papel fundamental, pues considera el carácter histórico y heterogéneo (desde el punto de vista social, cultural, económico y político) de cada porción del planeta, el cual toma forma en y desde sus actores sociales, pero que no puede concebirse sin el papel preponderante que tienen los recursos naturales en la determinación heterogénea de la estructura económica donde interactúan aquéllos (Sepúlveda et al., 2003; FAO, 1999).

Por lo anterior, un par de planteamientos parecen interesantes, los cuales manifestaron desde hace unos años Sepúlveda et al. (2003), Echeverri et al. (2003), Portilla (2003), Miranda (2003), entre otros autores, con su enfoque territorial del desarrollo (ETD) y con el carácter multifuncional de la agricultura y la tierra (CMFAT) propuesto por la FAO (1999). Estos enfoques amplían el conocimiento de lo que entendemos por rural, ya que no considera a la producción como la función única ni la más importante de la agricultura y la tierra, sino -además de lo dicho- también se relaciona con el patrimonio histórico y cultural de las sociedades, el esparcimiento y, más actualmente, con el retorno de las personas que han migrado.

De esta manera, ambos enfoques plantean que lo esencial es la integración de espacios, agentes, mercados y políticas relacionados con el mundo rural. Busca, por tanto, integrar los territorios rurales interna y externamente con el resto de la economía de cada país, su revitalización y reestructuración progresiva, así como adoptar nuevas funciones y demandas. Sin embargo, aborda poco el efecto del mundo urbano en el rural, lo cual se tiene que complementar con otros planteamientos.

Contrario al enfoque economicista y neoliberal del desarrollo rural que se tiene en buena parte de Latinoamérica -y particularmente en México--, el ETD destaca la importancia de las políticas de auténtico ordenamiento territorial, la importancia también de la autonomía y autogestión de los grupos sociales como complemento de las políticas de descentralización, privilegia los conceptos de cooperación, de corresponsabilidad y de inclusión económica y social. Este enfoque potencia la visión convencional de manejo de recursos naturales desde una perspectiva de protección del medio ambiente y de producción de alimentos y otros productos en forma inocua, para favorecer una economía territorial que incorpore elementos de otras actividades no agrícolas de la economía regional y de la economía de recursos naturales. 
Estos enfoques también buscan trascender la visión neoliberal de acumulación y transnacionalización del capital (dinero y bienes) y subraya la importancia de los otros tres tipos de capital: el humano (la capacidad y habilidades de las personas), el social (las relaciones y redes que facilitan la gobernabilidad) y el natural (la base de recursos naturales). De ahí que ponga especial énfasis en fortalecer la capacidad cultural y política de las sociedades rurales promoviendo esquemas de cooperación que se adapten a las distintas demandas de los actores de los territorios; es decir, la diversidad natural y la heterogeneidad política de cada territorio deben enfrentarse con estrategias diferenciadas para cada uno de ellos.

Aunque sus planteamientos parecen relativamente sencillos de enunciar, no lo son a la hora de aplicarlos, pues implican tener un ambiente favorable y políticas que garanticen la estabilidad y la equidad social, cultural, política y económica de las colectividades humanas, lo cual significa un gran esfuerzo de las fuerzas políticas para resolver sus problemas y diferencias.

En el cuadro 2 se presenta información que da una idea un poco más esquemática de las principales virtudes de estos dos enfoques.

\subsection{La importancia de la revaloración de los actores sociales y de la reorganización y caracterización de los territorios urbano-rurales}

Sin embargo el problema es complejo; debemos integrar una unidad de análisis territorial, o región de estudio, con base en lo que como humanos limitados podemos entender, sin separarla del proceso de desarrollo y vinculación global, que rebasa muchas veces nuestra comprensión individual. Afortunadamente el soporte físico de la transformación de la sociedad tiene manifestaciones territoriales que ahora son motivo de estudio de regionalistas, geógrafos, sociólogos, antropólogos, economistas, ecólogos y otros investigadores.

Ciertamente, se han hecho infinidad de clasificaciones como las que plantea la llamada nueva economía geográfica, los modelos de competitividad exportadora, y los medios innovadores y las regiones que aprenden, pero en éstos, de manera general, se considera a la región como subordinada a las actividades económicas, haciendo énfasis en que el territorio debe vincular lo local a lo global, desde el punto de vista de la homogenización al mercado internacional (Boisier, 2003).

En estos modelos la tecnología juega un papel preponderante y con frecuencia el espacio se organiza en distritos industriales, áreas especializadas de producción y redes jerárquicas de relaciones, donde en general el sector agrario o agrícola se considera inmóvil y marginal. El espacio es externo y contenedor, porque en este enfoque no se le considera capaz de 
explicar las causas de las localizaciones, por lo que es visto como homogéneo y plano.

En particular, algunas propuestas teóricas como la en su momento llamada nueva geografía económica, en la que el economista Paul Krug$\operatorname{man}^{12}$ es uno de sus principales exponentes, le ha dado mayor importancia al espacio sobre el tiempo, y los principales actores son de igual manera el mercado y las industrias, pero organizados en distritos o zonas industriales, aunque considera a la comunidad local, pero con su propio sistema de valores. En la práctica, sus propuestas denotan que algunos elementos del territorio (principalmente los que se refieren al medio ambiente) son sólo externalidades que no importan demasiado en el proceso de acumulación de capital.

Frente a estas posiciones, nos parecen más apropiados otros planteamientos como la teoría del crecimiento endógeno, las teorías radicales y posfordistas y la teoría del capital social, de las cuales algunos de sus teóricos pioneros han sido Coraggio, Pradilla, Le Corbusier y Lefevbre, y han hecho contrapeso al plantear que el enfoque debe centrarse en las actividades humanas (que algunos llaman rutinizaciones) y en aspectos como la tercera vía, que tienen que ver con la justicia social, las nuevas relaciones individuo-comunidad-Estado, y la propia democracia. En esta posición, la región es análoga a una convergencia donde hay integración social y sistémica (intersección de las actividades de rutina de los diferentes individuos), y donde la regionalización es una estación o un conglomerado amplio de interacciones.

En el concepto de territorio que nos interesa, el poder de los actores es un concepto transformador del mismo, cuyas interacciones y rutinas de contacto crean el espacio. En este enfoque, la articulación del tiempo con el espacio es más completa, porque aglutina elementos de acuerdo con su proximidad, constituido fundamentalmente por la vida social, aunque limitada por la indivisibilidad del cuerpo humano y su lapso finito de vida. Como se ve, los actores son todos los individuos involucrados en el desarrollo y esto inspira el presente trabajo.

Sin embargo, como menciona Castells (1996), es necesario reconocer que existe una realidad globalizadora, la cual no sólo es la nueva morfología socioterritorial emergente en nuestras sociedades, sino también es la lógica dominante, donde los flujos se entremezclan en una complicada malla de redes que se mueven a la velocidad de la luz y operan mediante las tecnologías de la información, concretan procesos y funciones que dominan nuestras sociedades. Y de alguna manera tenemos que buscar

${ }^{12}$ Algunos de sus principales teóricos pueden ser, además de Krugman, Leborgne, Hirschman, Myrdal, Gallup, Sachs y Mellinger (Boisier, 2003: 4, quien cita a H. W. Armstrong, 2002: 232-242). 


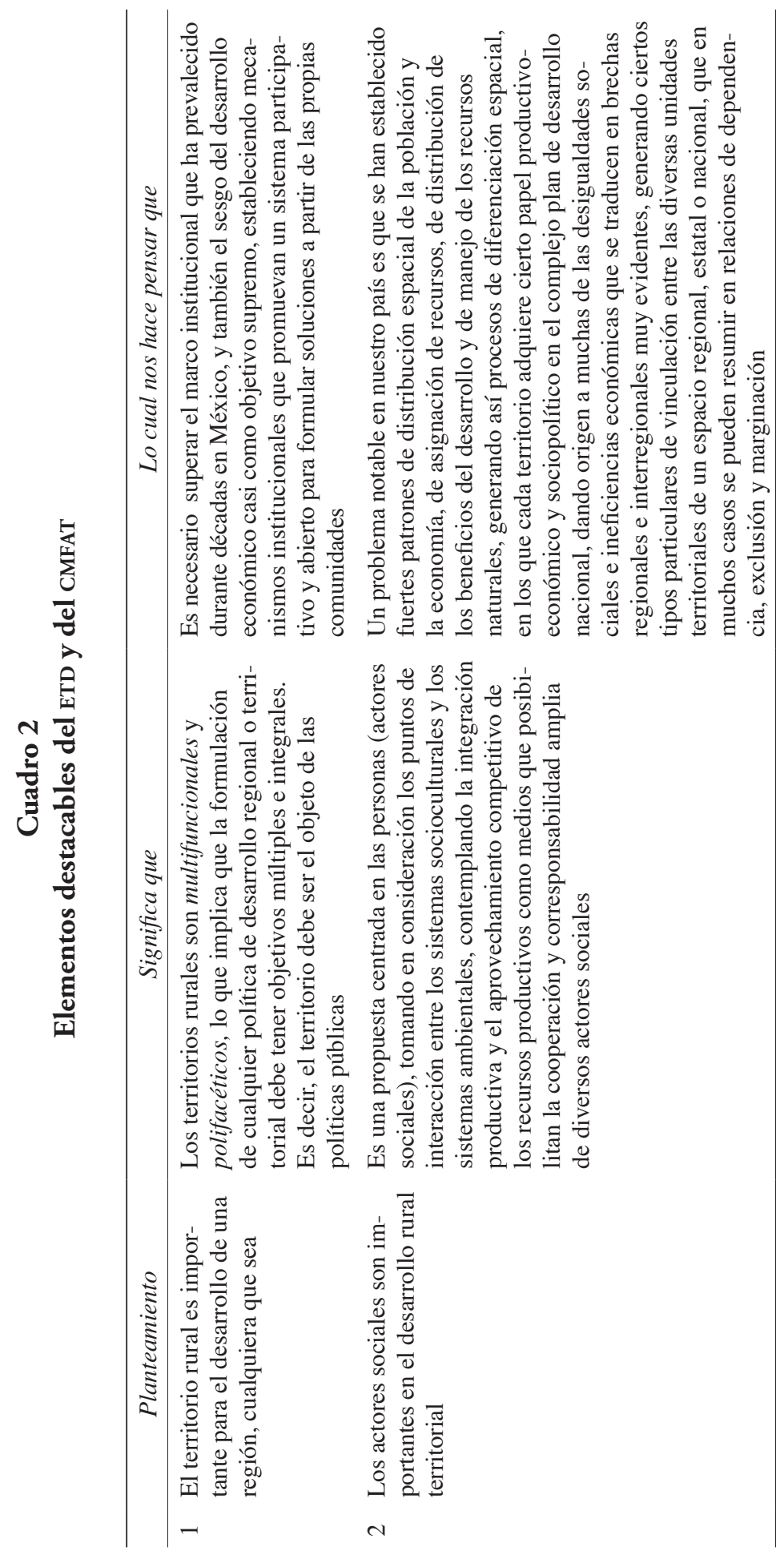




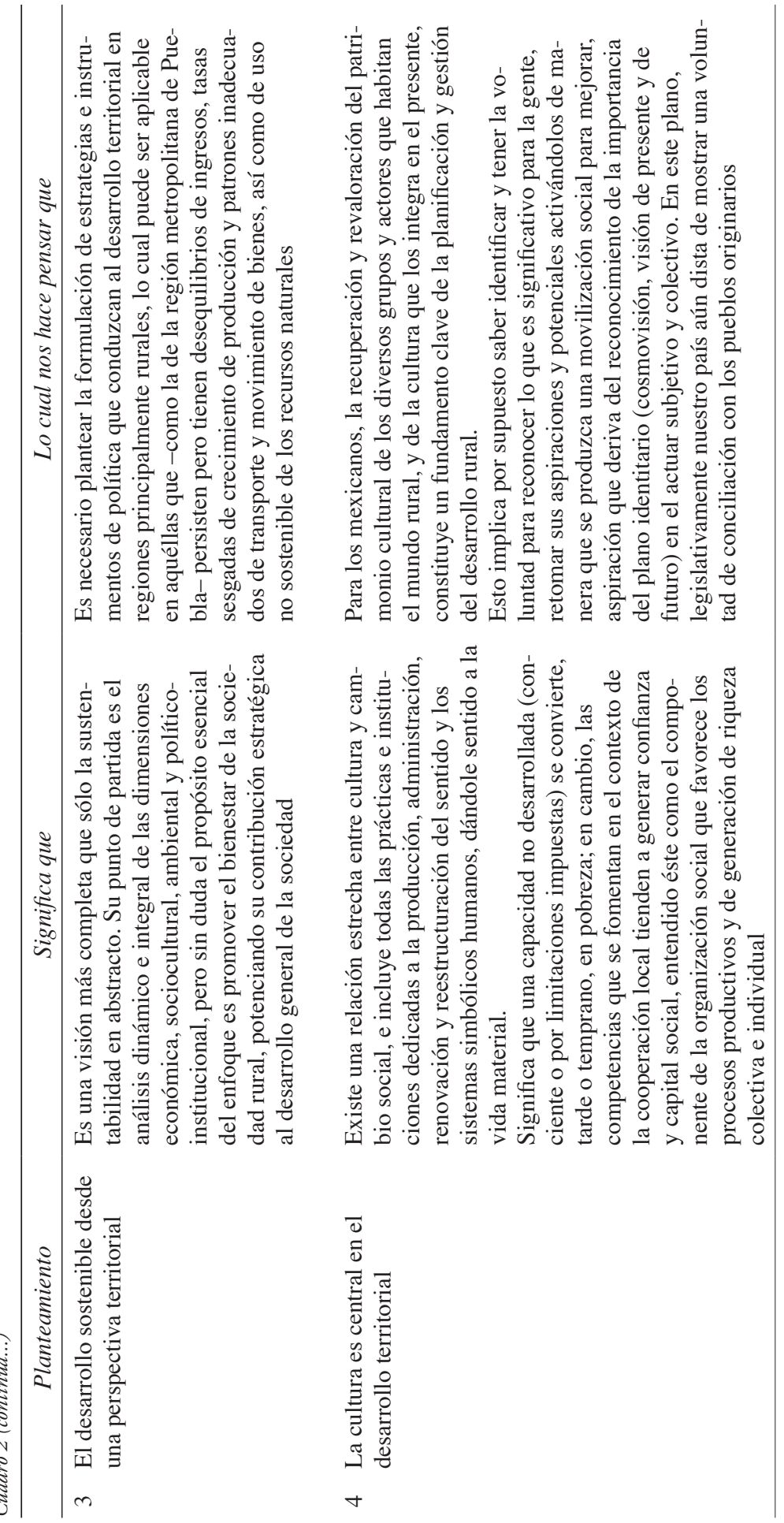




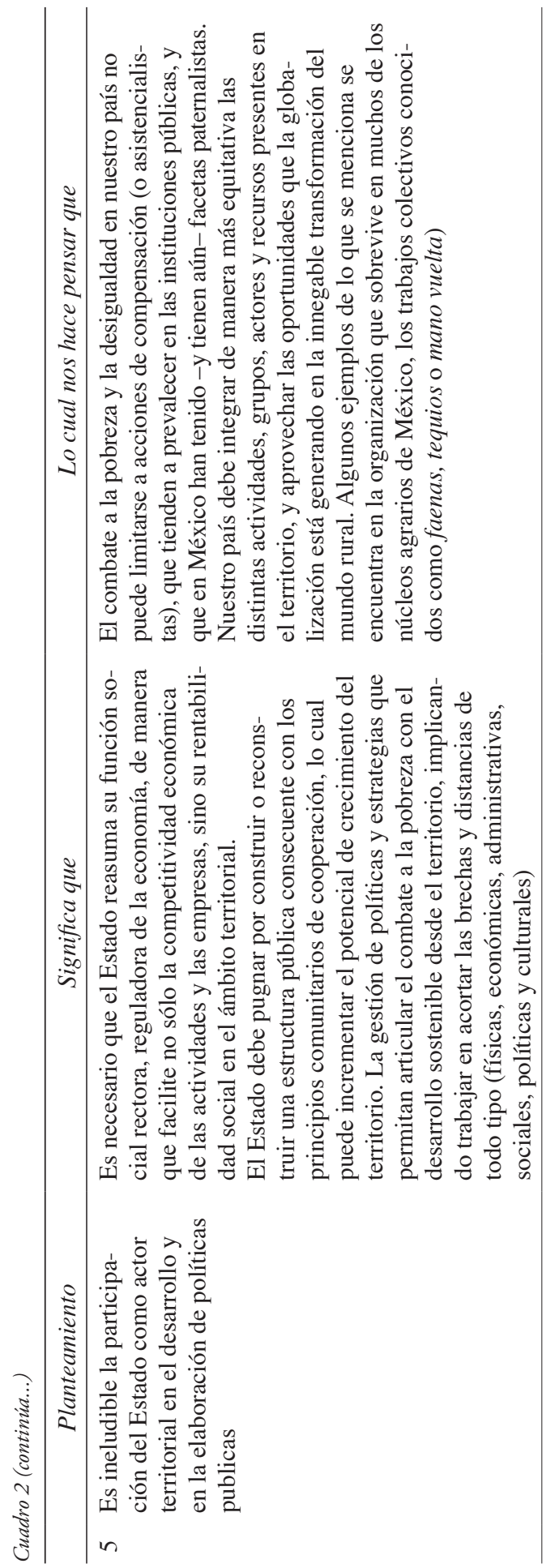




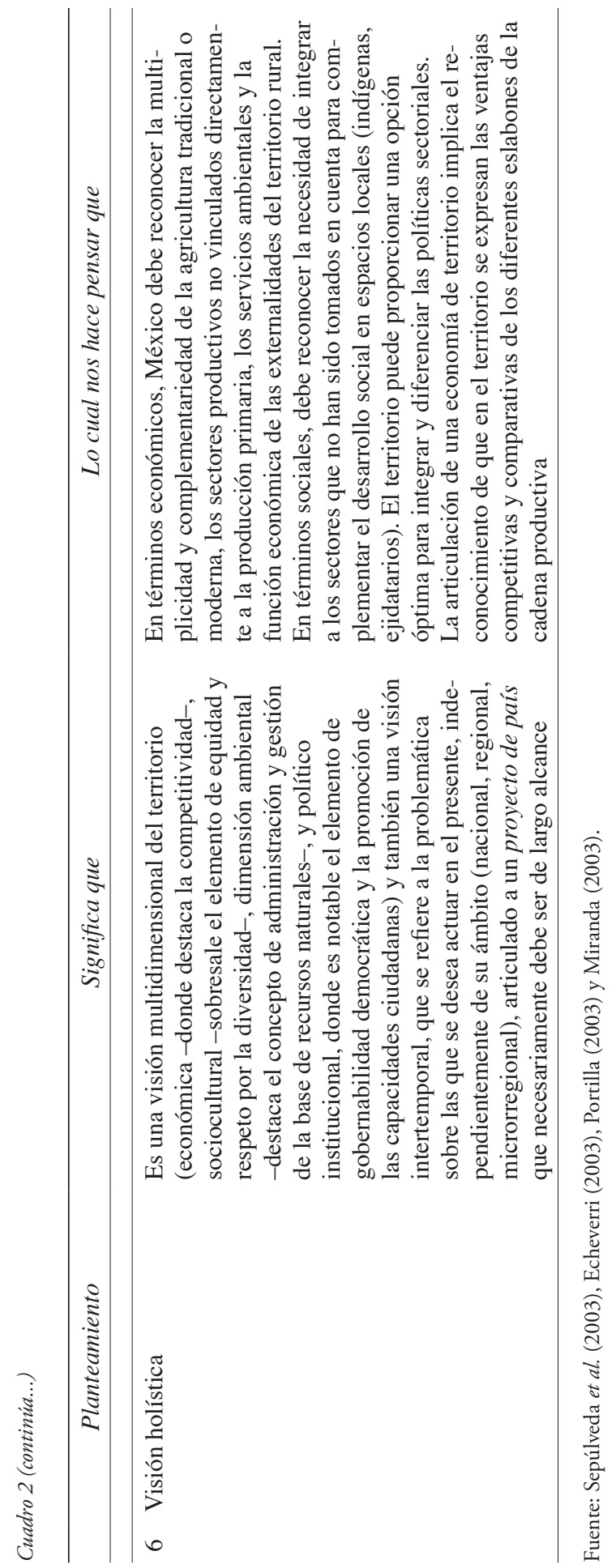


conciliarlas con aquel espacio donde se desarrolla la vida cotidiana de la gente y en el que se establecen, por tanto, las principales relaciones entre las personas a través de su cultura y su historia.

Aunque es difícil predecir las consecuencias si no se toma en cuenta a los actores rurales, los conflictos actuales, como los observados en la RMP, son un buen indicador de que éstas pondrían en grave riesgo el equilibrio regional en todos sus ámbitos. Por esto, es importante superar la visión convencional del capital en la dinámica económica actual (valores de uso y cambio, acumulación y transnacionalización de capital), al destacar la importancia de crear capital humano (capacidades de la personas), desarrollar capital social (relaciones, redes, etc., que facilitan la gobernabilidad y amplían el acceso a servicios básicos) y mantener y valorar el acervo de capital natural (base de recursos naturales) mediante el fortalecimiento de las capacidades culturales y políticas de la sociedad de esta región metropolitana, por lo que se debe reconsiderar como actores importantes a las organizaciones y comunidades rurales y agrarias.

Con una verdadera visión de desarrollo integral, la agricultura y la utilización correspondiente de las tierras también generan una amplia gama de productos, y otros servicios no alimentarios, mediante la configuración del medio ambiente y la afectación de los sistemas sociales y culturales, y con la contribución al crecimiento económico. Por esto, si en verdad se quiere promover un mayor equilibrio rural-urbano, en el tema de inversiones es necesario impulsar el desarrollo integral no sólo de la ciudad, sino también del campo, por lo que es fundamental garantizar mayores inversiones en el ámbito rural, las cuales son esenciales para garantizar la estabilidad social y política, fomentar la competitividad de la agricultura y las actividades económicas rurales, crear empleo rural, agrícola y no agrícola, que apoye un nivel aceptable de vida en las zonas rurales.

Vale la pena resaltar que ante las nuevas dinámicas y políticas de países que tradicionalmente son receptores de migrantes, como Estados Unidos, esta acción también permite crear el ambiente apropiado para motivar a este capital humano para que regrese.

Con este panorama, es que se decide llevar a cabo una investigación doctoral que transcurrió durante los años de 2003 a 2008, cuyo objetivo central se enfocó a identificar y analizar para la región metropolitana de Puebla los elementos y actores relevantes del proceso de reestructuración y cómo inciden éstos en los territorios rurales -en particular en los ejidos-, destacando los elementos económicos y políticos del proceso y los elementos territoriales que son afectados por el mismo, con la finalidad de proponer una estrategia alternativa de desarrollo regional con enfoque territorial. 


\section{Aspectos metodológicos}

La metodología implicó enfocar el conjunto regional como un complejo sistémico, por lo que se vio la necesidad de diseñar un método de análisis territorial, el cual intentó discernir la función que tienen los territorios rurales en la actualidad, si todavía son viables e importantes, con la finalidad de intentar demostrar que pueden -y deben- aportar elementos importantes para el proceso de desarrollo y equilibrio regional. En este sentido, se consideró importante plantear las teorías y metodologías que hablan de la necesaria construcción de un proyecto político de desarrollo para cada región, así como de los efectos regionales que las políticas económicas aplicadas institucionalmente han causado, con independencia del análisis del discurso de los que hacen la política, lo cual implica considerar aspectos fundamentales como las relaciones entre actores e instituciones públicas (para analizar relaciones de poder), las actividades económicas y culturales en el territorio, la forma en que los actores han aprovechado los recursos, cómo se inserta la región en los procesos globales, sus aspiraciones al respecto, etcétera.

Para esto se decidió abordar el problema en dos grandes aspectos: como un estudio de caso y mediante un análisis hemerográfico. Para el primer aspecto metodológico, resultó harto difícil imaginar la forma de estudiar el fenómeno de la relación campo-ciudad de la ciudad de Puebla en su contexto real, porque de antemano sabíamos que los límites entre el fenómeno en sí y su contexto no eran claramente evidentes, pero era necesario intentar explicar resultados empíricos mediante el examen de mecanismos causales. $\mathrm{Y}$ en este sentido no hay forma más poderosa que estudiar la conducta de las personas (actores) involucradas en el fenómeno, pero también buscar cómo mirar hacia su pasado y origen. Por lo anterior, se realizó un estudio histórico que se remontó a la misma fundación de la ciudad, entre 1531 y 1532, para analizar cómo mediante las diferentes etapas de la ciudad (Colonia, Independencia, Reforma, Revolución, etc.) se fue modificando la relación del mundo urbano y el rural. Para el estudio de los actores se diseñaron dos instrumentos de campo, uno enfocado a la investigación de la historia agraria de los ejidos desde la dotación hasta sus movimientos agrarios más recientes (expropiaciones, regularización de la tenencia de la tierra, dominio pleno, etc.), y otro para obtener información de los actores vivos (ejidatarios, órganos de representación, asamblea) que consideraron cinco grandes dimensiones de estudio: ambiental (aportación de servicios ambientales); social (incorporación de propiedad social al desarrollo urbano, adopción de dominio pleno y/o aportación de tierras a sociedades mercantiles); cultural (gobierno y normas consuetudinarias, lenguaje, identidad, artes y artesanías); 
económica (agricultura, actividades económicas no agrícolas, otras actividades rurales) y politico-institucional (defensa del territorio por actores ejidales y por otros actores civiles). Un mayor detalle de las dimensiones y sus variables se muestran en el cuadro 3 .

En cuanto al estudio hemerográfico, se decidió tomar como referencia a partir del año 2003 a 2006 las noticias destacadas de los principales diarios locales impresos y electrónicos, como La Jornada de Oriente (diario regional de La Jornada nacional), El Sol de Puebla, El Sol de Tlaxcala, Milenio Puebla, los diarios digitales Sintesis, Intolerancia, Opinión, entre otros, visitando sus páginas electrónicas y sus versiones impresas en la hemeroteca "Juan Nepomuceno Troncoso", del Instituto Cultural Poblano, que depende de la Secretaría de Cultura del gobierno del estado. El total de casos estudiados fueron 61, presentados y analizados en cuadros matrices.

Para el caso que nos ocupa, este tipo de investigación social se consideró una fuente valida de información para la investigación social, sin embargo, hay que reconocer que todavía no adquiere gran relevancia porque en muchas ocasiones se tiene desconfianza al estatus en el que se encuentra el periodismo a rasgos generales, y también porque los estudios que hacen uso de este tipo de fuentes exigen un arduo proceso de investigación, en el que se consideran los elementos que componen el medio impreso, así como los procesos comunicativos que subyacen en su interior. Dichos elementos constitutivos no sólo se refieren al texto y la imagen periodística, sino también a los componentes paratextuales que orientan su interpretación, así como a la estructura de cada publicación -diseño y diagramación-, que involucran la lectura, comprensión y formación de creencias y usos sociales de la información.

Los resultados obtenidos de la investigación, en la cual se estudiaron cinco ejidos conurbados, tres de los cuales fueron totalmente reestructurados entre 1990 y 1994, San Andrés Cholula, San Bernardino Tlaxcalancingo y Santa María Tonanzintla, y dos más que se encuentran en proceso, San Miguel Canoa y Santa Ana Xalmimilulco (cuadro 4), muestran que los principales elementos de política utilizados en el proceso de reestructuración territorial, como se pudo observar, en estos ejidos son:

1) El uso de instrumentos de política (leyes, instituciones, facultades de funcionarios públicos).

2) La intervención de la autoridad gubernamental para llevarlos a cabo.

3) Campañas de inducción para que los ejidatarios desincorporen las tierras ejidales. 


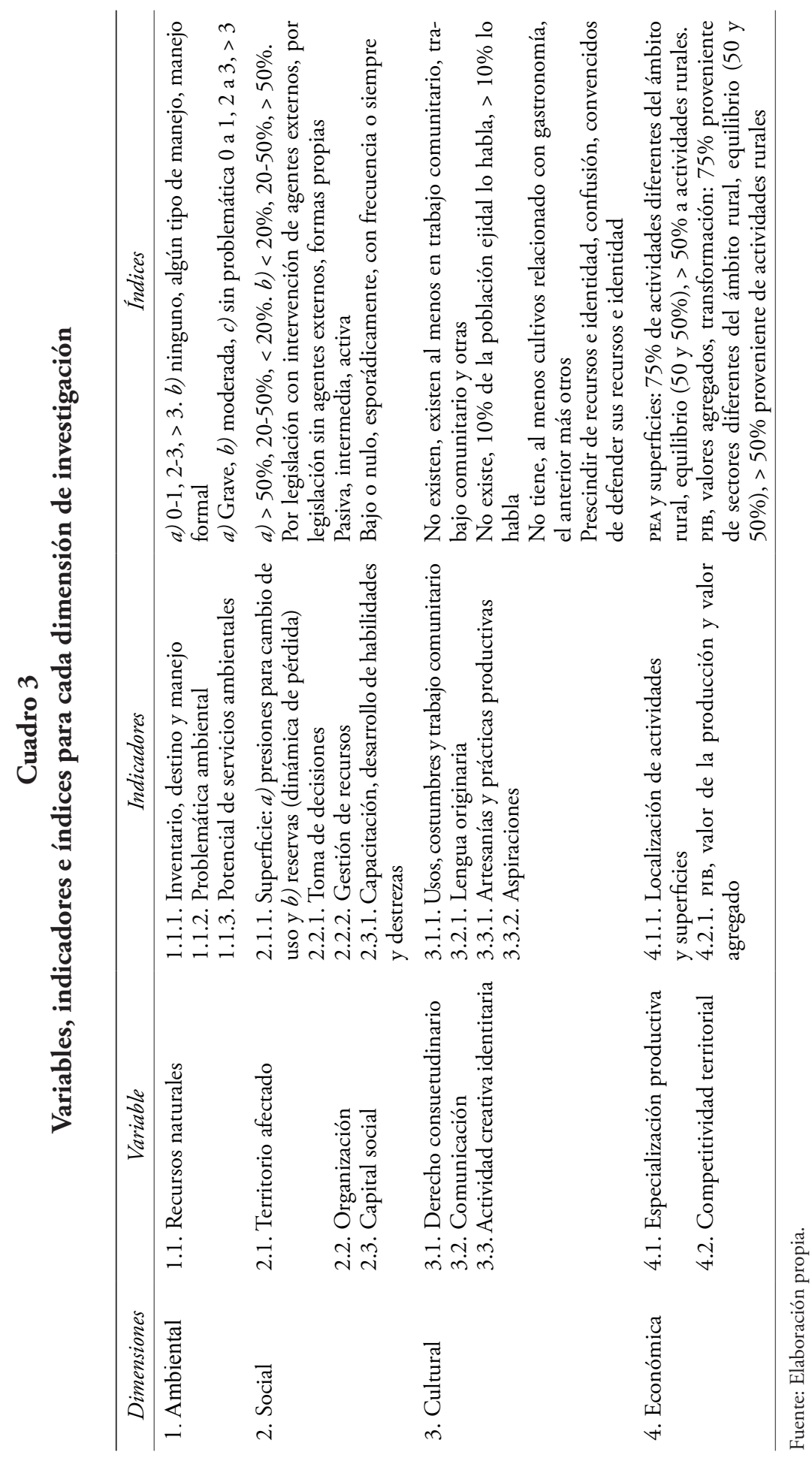




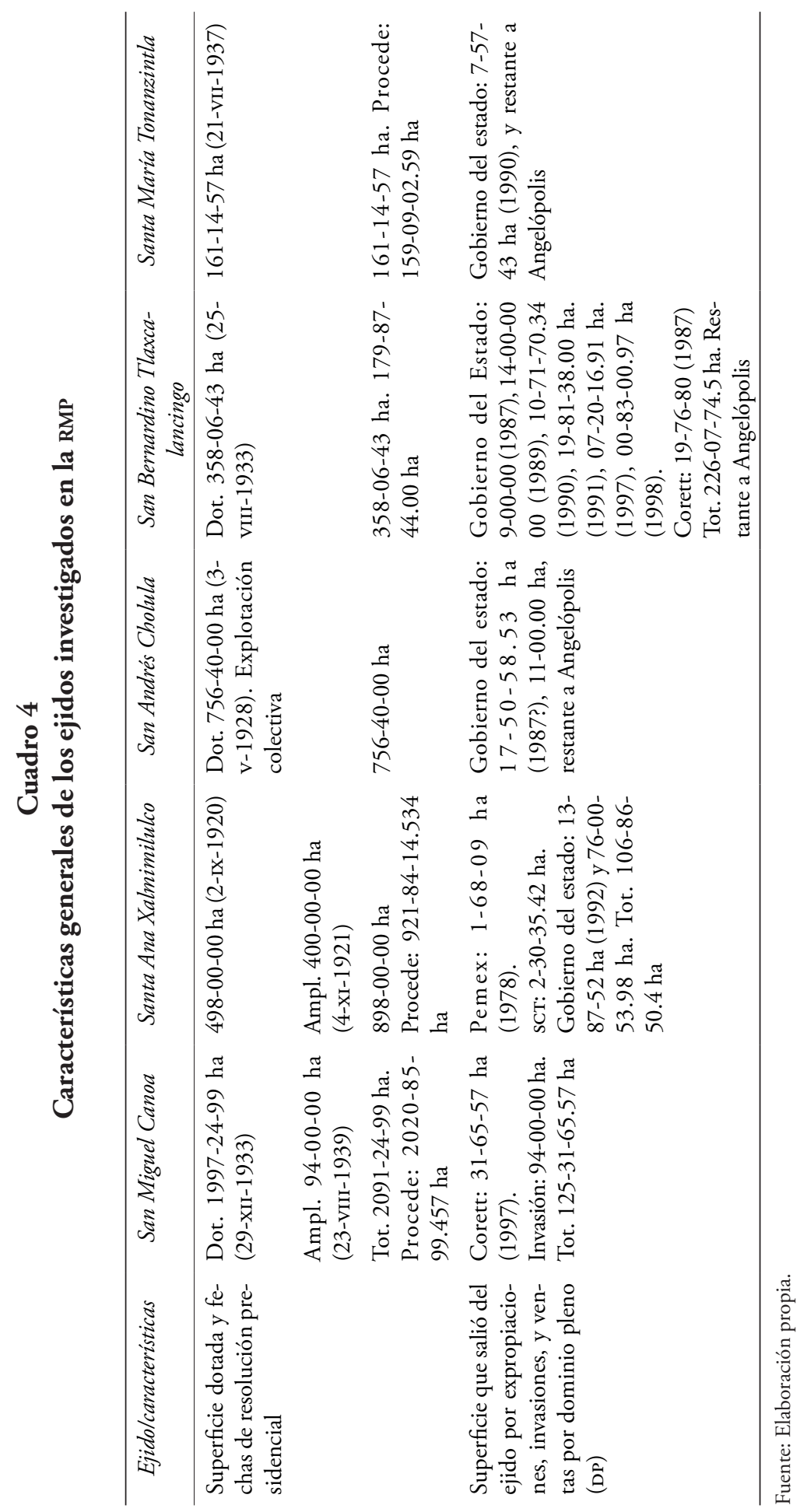


Muy relacionado con lo anterior, los principales elementos de carácter económico que se aplicaron para fortalecer los elementos de política, y que son el verdadero trasfondo de la reestructuración territorial son:

1) Creación de fideicomisos y organismos de apoyo empresarial para que empresas se asienten en el territorio y puedan desarrollarse, con el objetivo de generar empleos e incentivar la economía regional.

2) Subsidios y apoyos económicos para el crecimiento de las empresas, tanto en los parques industriales como en lugares adyacentes.

3) Permisos y concesiones para que se puedan ocupar las tierras ejidales o adyacentes, antes de su cambio y regularización de régimen en la tenencia.

4) Subsidios, apoyos económicos y campañas legales para que los ejidos desincorporen la tierra de su régimen ejidal, mediante programas institucionales.

5) Incentivación del mercado de tierras ejidales y rurales, para promover que se dé el cambio de uso a suelo urbano.

\section{Análisis sobre resultados}

Como se puede apreciar, un rasgo característico del proceso de reestructuración es la acción planificada desde el ámbito de las instituciones y el gobierno hacia el debilitamiento de la estructura ejidal y rural, recurriendo con frecuencia al argumento de la desvaloración de la tierra bajo este régimen, mediante la justificación de una supuesta necesidad de transformación a usos del suelo de tipo urbano, utilizando métodos poco éticos en relación con el от у coercitivos en diferentes modalidades, donde consecuentemente surgen actores que son hábiles en este proceso y que aprovechan fenómenos sociales que de por sí se dan en todas partes, como los asentamientos irregulares de grupos marginados.

Este proceso que se ha seguido durante más de tres décadas ha contribuido a provocar un daño social y cultural que ha llevado a que habitantes de los diversos ejidos estudiados tengan poca disposición a participar en apoyar a sus órganos representativos y, en general, para seguir sustentando su modo de vida rural.

Prueba de esta afirmación es que entre los resultados observados en los cinco ejidos, se pudo constatar el casi nulo desarrollo de capital social y humano de los núcleos agrarios, así como la ausencia de figuras asociativas o alguna otra forma de organización activa dentro de los ejidos (cuadro 5).

Esta característica de ausencia de organizaciones con actividad positiva percibida en los ejidos, como se aprecia en el cuadro 4, trae como 


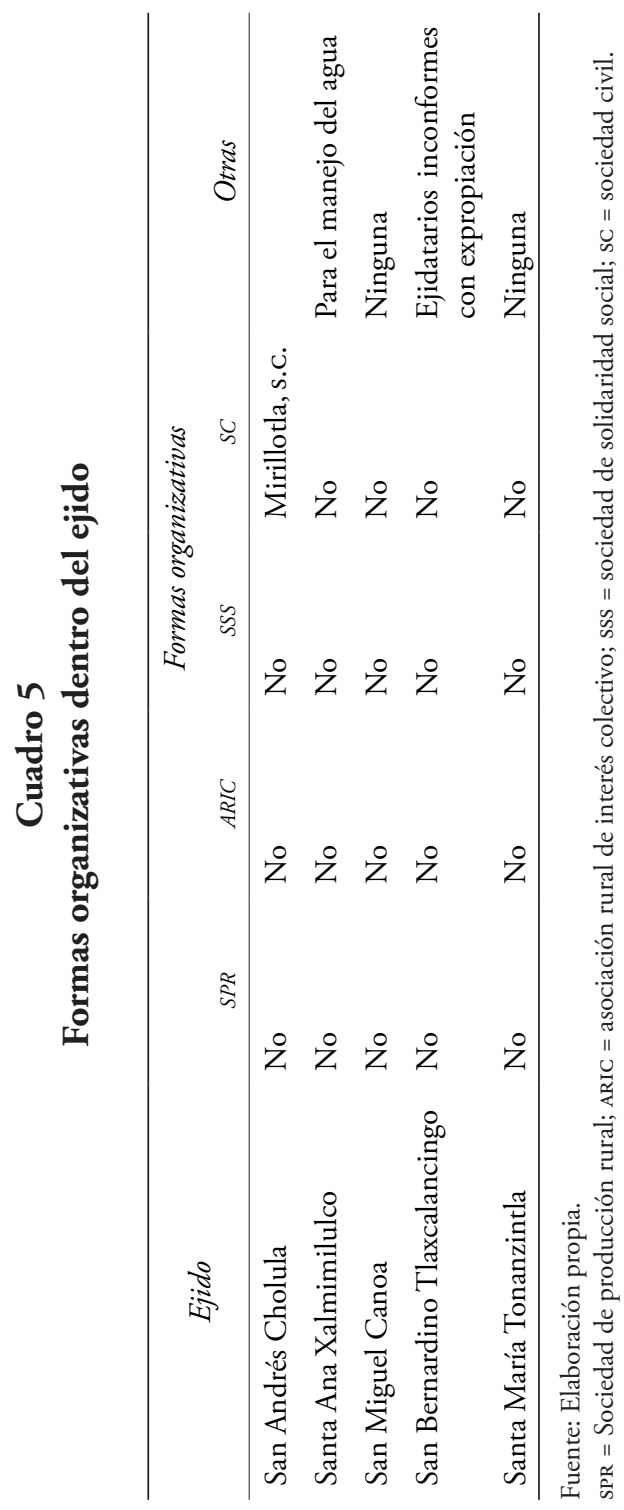


consecuencia la necesidad del ejido de recurrir a agentes externos para que les ayuden a resolver sus problemas y también para tomar decisiones, a excepción de Tonanzintla, que de acuerdo con lo que informaron, se bastan con lo que la legislación agraria les permite. Cabe señalar que en el caso de Tonanzintla, este ejido ya no tiene tierras que administrar, y sus asuntos en realidad son pequeños casos relacionados con el finiquito del proceso de expropiación y algunos otros.

Mediante la técnica de análisis hemerográfico con datos recopilados durante un periodo de cuatro años (2004-2007) de los principales diarios de la región, se concluyó que de 61 casos relevantes, 35\% de los actores involucrados eran opositores sistemáticos (lo cual aún es un cálculo conservador, pues cada ejido es un conjunto de actores). En las instituciones y funcionarios municipales y federales también se observó un papel relevante en este proceso de oposición, así como organizaciones civiles y personas que sin pertenecer a alguna agrupación social, se preocuparon por defender territorios rurales (gráfica I).

Vale la pena insistir en que es la otra parte de la sociedad la que le está haciendo frente al proceso, aquélla que se encuentra en el ámbito del mundo rural y se ha organizado para ello, como organizaciones civiles, agrarias (ejidos y núcleos todavía rurales), pero también de ciertos sectores institucionales, como las universidades. Investigadores y académicos de diversas instituciones, como la Benemérita Universidad Autónoma de Puebla (BuAp), el Centro Universitario de Prevención de Desastres Regionales (Cupreder), la Universidad Popular Autónoma del Estado de Puebla (UPAEP), entre otras, se han sumado desde diferentes cauces para señalar los inconvenientes de estas políticas, proponer medidas en torno a cuestiones ecológicas, de prevención de enfermedades, de ordenamiento territorial y ecológico, entre otros temas.

Es por esto que podemos entender el desarrollo en la RMP como un proceso contradictorio y paradójico, ya que aparenta ser fuerte y conciso, pero en el fondo está acumulando tensiones en sus territorios que más temprano que tarde pondrán de relieve su vulnerabilidad. En ésta, considerando la clasificación que hace Milton Santos (1996: 92-96), se agudizan las contradicciones entre lo externo y lo interno, de lo nuevo contra lo viejo, de la que debería ser la función del Estado contra los intereses del mercado.

Por lo anterior, explícitamente en el proceso seguido en la RMP se deben eliminar los sesgos antiagrícolas y antirurales en las políticas que se pretenden implementar: mediante el reconocimiento de su importancia y contribución al bienestar de la sociedad, y la construcción de un marco institucional que favorezca el desarrollo sostenible de la agricultura y el medio rural. En este marco, es importante la modernización de la 


\section{Gráfica I \\ Actores en contra de la reestructuración}

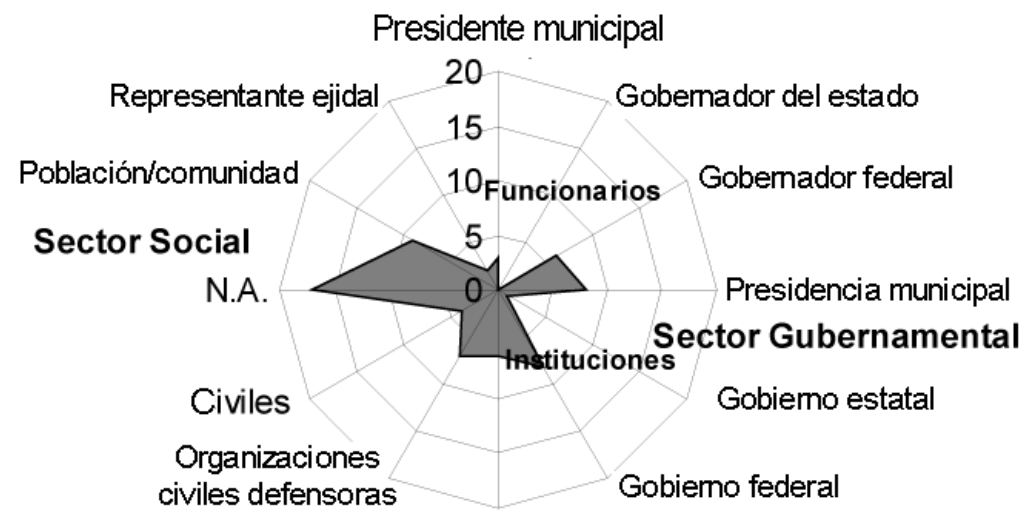

Educación y otras

$\square$ Incidencia en el proceso

agricultura -que sigue siendo relevante en la región-, así como el fortalecimiento de los servicios de apoyo a la producción y el comercio agroalimentarios, reduciendo las brechas de conocimiento, información y tecnología en este sector, por lo que se debe apoyar a las organizaciones y comunidades rurales y agrarias - de las cuales ya se han dado algunos datos significativos- para mejorar sus capacidades, invirtiendo más en la formación de capital humano y promover el diálogo entre los diversos actores sociales involucrados (gobiernos estatales y municipales, sociedad civil inmersa en las luchas territoriales, instituciones pertinentes, etc.), con la finalidad de propiciar un ambiente favorable para las empresas rurales (agrícolas y no agrícolas) en estructuras interrelacionadas, así como fomentar los mercados para los productos que de ellas se obtengan, facilitando su acceso.

La importancia de los aspectos ambientales implica redefinir la concepción de lo rural a partir del papel preponderante que juegan los recursos naturales en la determinación de la estructura económica de un territorio, al ser éstos una característica inherente a la ruralidad, donde los principales elementos de dicho modelo de gestión son el reconocimiento del papel articulador de los recursos naturales, ya que, por ejemplo, un mayor número de habitantes en el área metropolitana de Puebla y Tlaxcala implica más demanda de servicios, entre los que se encuentra el agua, por lo que es importante considerar a los mercados de servicios ambientales, especialmente el pago por servicios de producción de agua, deriva- 
do de la conservación y manejo sostenible de las áreas naturales protegidas ubicadas en los volcanes Iztaccíhuatl, Popocatépetl, La Malinche y Zoquiapan, y las reservas ecológicas de los cerros Amalucan, Comalo, Mendocinas, Tepeyac, Totolqueme y Zapotecas, los cuales a su vez, en conjunto con el parque ecológico Flor del Bosque, pueden ofrecer mejores servicios de ecoturismo y turismo rural, entre otros.

Por eso, políticas regionales como las de la RMP, aunque visualizan una región con ubicación geográfica privilegiada y con grandes ventajas potenciales para capitales nacionales e incluso internacionales, son en realidad políticas de reestructuración territorial, no de ordenamiento territorial. La intención de cambio de uso del suelo para destinarlo casi exclusivamente a vivienda, industria y maquila puede ser un grave error, pues aunque se reconoce la importancia de las cadenas productivas y de valor agregado, de nada servirían acciones que no vayan encaminadas a articularlas al territorio en una economía intrínsecamente multisectorial, donde predomine el deseo de alcanzar objetivos múltiples y de articular procesos productivos a mediante conceptos como clusters, circuitos espaciales de producción ${ }^{13}$ y denominación de origen, pero también de conceptos como soberania alimentaria, multifuncionalidad territorial y autonomía.

\section{Conclusiones}

Podemos concluir, primero, que en la RMP existe un proceso de reestructuración territorial, el cual podemos considerar conceptualmente para este caso como un proceso territorial donde deliberadamente se conduce a la economia de una región hacia sectores determinados y hacia el predominio de lo urbano sobre lo rural, favoreciendo el cambio de uso del suelo e incentivando el mercado descontrolado de tierras de propiedad social, sin considerar aspectos básicos de ordenamiento territorial, de desarrollo sostenible, de protección de la cultura y de las estructuras sociales locales, lo cual favorece sólo a un reducido grupo de actores.

Las principales contradicciones observadas entre la RT y el OT para el estudio de caso de la RMP son:

- El establecimiento deliberado de industrias y áreas residenciales, sin importar mucho su delimitación y regionalización.

${ }^{13}$ Esta categoría propuesta por algunos autores, como Santos (1996), busca sustituir los tradicionales conceptos sobre cadenas agroalimentarias, reconociendo el vínculo entre la globalización y las diversas etapas por las que pasa un producto desde el inicio del proceso de producción hasta llegar al consumidor final, donde habría que considerar el uso y consumo del suelo, dado que el dinamismo que algunas empresas maquiladoras de exportación hacen que el territorio pierda sus características de lugar, convirtiéndolo en un territorio-mercancía de los espacios de flujo (Posada, 1999). 
- La irracional afectación de los recursos naturales y la explotación de los mantos acuíferos.

- La poca importancia de los territorios rurales como generadores de alimentos, materias primas y servicios.

- La visualización de lo urbano y rural como contrarios, en lugar de enfocarlos como complementarios dentro de una perspectiva sustentable.

- Su estrategia consiste en el incremento de factores de localización regionales a costa de la expropiación de territorios rurales (básicamente de propiedad social), acompañados de facilidades fiscales con fondos públicos.

- Su finalidad es orientar la estructura y función económica regional, pero favoreciendo sólo a algunos sectores de la sociedad.

De esta manera, el concepto adecuado de ordenamiento territorial para una región como la RMP se puede considerar, contrario sensu, como la expresión normada, consensuada y legislada de políticas, planes, proyectos y actividades que regulan los aspectos socioculturales, económicos y ambientales de una sociedad urbana-rural que aspira a mejorar su nivel de vida.

En el proceso de RT el espacio y el territorio se transforman en una relación de dominación, marginación y exclusión de lo urbano sobre lo rural, porque lo consideran innecesario o poco competitivo.

Los territorios y los actores rurales se debilitan o tienden a desintegrarse, reorientando sus actividades económicas hacia las no rurales, lo que significa una pérdida sociocultural.

Por tanto, el enfoque del desarrollo se debe centrar en las actividades humanas, y las relaciones que sostiene con la colectividad y el Estado.

El territorio debe articularse a una economía que se entienda como intrínsecamente multisectorial, sin perder de vista conceptos como soberanía alimentaria, multifuncionalidad y autonomía.

La caracterización de los territorios urbano-rurales debe considerar como aspecto central a los actores, su cultura y su poder de transformación del territorio, pero sin menoscabo de la influencia de procesos externos como la globalización.

De igual manera, el territorio debe caracterizarse no sólo por las bondades que puede o no aportar la agricultura, sino por su potencial capacidad de configurar el medio ambiente, y cómo puede afectar los sistemas sociales y culturales, contribuyendo al crecimiento económico, capacidad de recepción de migrantes e incremento del nivel de vida de la población regional. 
Es necesario superar la visión convencional actual que se caracteriza por los valores de uso y cambio, acumulación y transnacionalización de capital, enfocándolos a la importancia de desarrollar capital humano (capacidades de la personas), capital social (relaciones, redes, etc., que facilitan la gobernabilidad y amplían el acceso a servicios básicos) y mantener y valorar el acervo de capital natural (base de recursos naturales), mediante el fortalecimiento de las capacidades culturales y políticas de la sociedad de esta región metropolitana, por lo que se debe reconsiderar como actores importantes a las organizaciones y comunidades rurales y agrarias.

\section{Bibliografía}

Barbosa Cano, Manlio (1993), El crecimiento industrial del estado de Puebla. Caracteres económicos e implicaciones sociales en cien años de industrialización, Instituto Nacional de Antropologia e Historia, México.

Boisier, Sergio (2003), “¿Y si el desarrollo fuese una emergencia sistémica?”, Reforma y Democracia, 27, Caracas, p. 24.

Caravaca Barroso, Inmaculada (1998), "Los nuevos espacios ganadores y emergentes”, Revista EURE, 24 (73), Santiago de Chile, pp. 23-45.

Castells, Manuel (1996), The rise of the Network Society, Blackwell, Massachussets.

сіммүт (Centro Internacional de Mejoramiento de Maíz y Trigo) (1974), El Plan Puebla. 7 años de experiencias 1967-1973, El Batán, México.

Comité de Ministros a los Estados Miembros del Consejo de Europa (1984), Carta Europea de Ordenación del Territorio, Recomendación $\mathrm{R}(84)$ 2, adoptada el 26 de enero de 1984.

Echeverri, Rafael, Melania Portilla, Adrián Rodríguez y Sergio Sepúlveda (2003), "Desarrollo rural sostenible. Enfoque territorial", en Sinopsis 2003, Organización de Estados Americanos-Instituto Interamericano de Cooperación para la Agricultura, San José.

FAo (Organización de las Naciones Unidas para la Agricultura y la Alimentación) (1999), Documento expositivo: el carácter multifuncional de la agricultura y la tierra, FAO, Maastricht. 
Flores González, Sergio (2002), "La planeación urbana y el desarrollo regional sustentable en la zona metropolitana Puebla-Tlaxcala", en Actualidad de la investigación regional en el México Central, CRIM-Universidad Nacional Autónoma de México-El Colegio Mexiquense-El Colegio de Tlaxcala-Plaza y Valdés, México.

Gómez Orea, Domingo (2002), Ordenamiento territorial, Mundi-PrensaAgrícola Española, Madrid.

Gross, Patricio (1998), "Ordenamiento territorial: el manejo de los espacios rurales”, Revista EURE, 24 (73), Santiago de Chile, pp. 116-118.

H. Ayuntamiento de Puebla (1999), Ficha socioeconómica del municipio de Puebla, Ayuntamiento de Puebla, 1999-2002, México.

Hiernaux-Nicolás, Daniel (1990), "En la búsqueda de un nuevo paradigma regional”, curso internacional Nuevas tendencias en el análisis regional, 24 de septiembre de 1990.

INEGI (Instituto Nacional de Estadística, Geografía e Informática) (2004), "Cartografía básica”, www.inegi.gob.mx, 23 de diciembre de 2004.

Jiménez, Leobardo (1974), "El Plan Puebla: un programa regional para aumentar los rendimientos de maíz entre agricultores con pequeñas explotaciones", en сіммүт, El Plan Puebla. 7 años de experiencias 1967-1973, El Batán, México.

Mac Donald, Joan y Daniela Simioni (1999), Consensos urbanos. Aportes del Plan de Acción Regional de América Latina y el Caribe sobre Asentamientos Humanos, onu-CePal, Santiago de Chile.

Melé, Patrice (1994), Puebla: urbanización y politicas urbanas, Benemérita Universidad Autónoma de Puebla-Universidad Autónoma Metropolitana, Azcapotzalco, México.

Miranda Abaunza, Byron (2003), Capital social, institucionalidad y territorios: el caso de Centroamérica, Organización de Estados Americanos-Instituto Interamericano de Cooperación para la Agricultura-Servicio de Información Mesoamericano sobre Agricultura Sostenible, Managua-San José. 
Portilla Rodríguez, Melania (2003), "Actores sociales en el desarrollo rural territorial”, Sinopsis, 8, Organización de Estados AmericanosInstituto Interamericano de Cooperación para la Agricultura, San José, p. 8.

Posada, Marcelo (1999), "El espacio rural entre la producción y el consumo: algunas referencias para el caso argentino", Revista EURE, 25 (75), Santiago de Chile, pp. 63-66.

Rodríguez, Alfredo y Enrique Oviedo (2001), Gestión urbana y gobierno de áreas metropolitanas, CEPAL, Santiago de Chile.

Sagarpa (Secretaría de Agricultura, Ganadería, Desarrollo Rural, Pesca y Alimentación) (2005), Anuario estadístico de la producción agrícola 1999-2003, www.siap.sagarpa.gob.mx/ar_comdownload. html, 28 de julio de 2005.

Santos, Milton (1996). Metamorfosis del espacio habitado, Oikos-tau, Barcelona.

Sepúlveda, Sergio, Adrián Rodríguez, Rafael Echeverri y Melania Portilla (2003), El enfoque territorial del desarrollo rural, Instituto Interamericano de Cooperación para la Agricultura, San José.

Vélez Pliego, Francisco (2004), "Fichas de diagnóstico sobre temas críticos del municipio y ciudad de Puebla", La Jornada de Oriente, 17 de septiembre, Puebla.

Recibido: 23 de octubre de 2009. Aceptado: 7 de abril de 2010.

Héctor Bernal-Mendoza. Es licenciado en ingeniería agroindustrial; doctor en ciencias por el Colegio de Postgraduados. Es profesor-investigador de tiempo completo en la Benemérita Universidad Autónoma de Puebla (BUAP). Asimismo fue secretario académico en la Universidad Intercultural del Estado de Puebla (UIEP), organismo público descentralizado, de junio de 2006 a junio de 2008. Sus líneas de investigación actual son: enfoque territorial del desarrollo y desarrollo sustentable. Entre sus publicaciones destacan: "El proyecto histórico de la metrópoli poblana", suplemento Matria de La Jornada de Oriente, año 1, 1, Puebla, p. 3 (2007); "Desde la crisis capitalista. Reflexión sobre el desarrollo regional", suplemento Matria de La Jornada de Oriente, año 1, 22, Puebla, 
p. 3 (2008); en coautoría (coords.), Investigación multidisciplinaria en la sierra norte de Puebla, Colegio de Postgraduados-Universidad Intercultural del Estado de Puebla-Altres Costa Amic, México (2009).

Javier Ramírez-Juárez. Es doctor en ciencias por el Colegio de Postgraduados en Ciencias Agrícolas. Es profesor-investigador de tiempo completo en el Colegio de Postgraduados, Campus Puebla. Es investigador nivel II en el Sistema Nacional de Investigadores (SNI) y líder de la línea de investigación desarrollo rural sustentable del Colegio de Postgraduados. Ha sido profesor invitado por la Universidad de Toulouse Le Mirail. Sus líneas actuales de investigación son: sujetos sociales en el desarrollo rural territorial, y ruralidad, territorio y campesinado. Entre sus publicaciones destacan: "El sistema de usos y costumbres bajo el poder económico y político local en Matatlán, Oaxaca”, en J. Hernández (coord.), Ciudadanías diferenciadas en un estado multicultural, Siglo xxı, México, pp. 131-150 (2007); "Territorialidad y conflicto por el agua en Axocopan, Atlixco", en V. Vázquez et al. (coords.), Gestión y cultura del agua, Instituto Mexicano de Tecnología del Agua-Colegio de Postgraduados, México, pp. 169-192 (2006); "Lógica socioeconómica regional y pobreza rural: la ruralidad en el valle de Puebla y la cordillera del Tentzo, México", en J. Luzón y Ch. Stadel (coords.), Transformaciones regionales y urbanas en Europa y América Latina, Universidad de Barcelona, Barcelona, pp. 209219 (2003).

Ricardo Pérez-Avilés. Es doctor en sociología por la Universidad Nacional Autónoma de México (UNAM). Es profesor-investigador de tiempo completo y coordinador del Departamento Universitario para el Desarrollo Sustentable (Dudesu) del Instituto de Ciencias de la BuAp. Asimismo, es docente en el programa de maestría y doctorado en ciencias ambientales; en la licenciatura en sociología de la Facultad de Derecho y Ciencias Sociales; y en la carrera de ingeniería ambiental de la Facultad de Ingeniería, todas de la UAP. Es miembro del Comité Científico encargado de evaluar seis trabajos que se presentaron en el $8^{\circ}$ Congreso Internacional, $14^{\circ}$ Nacional de Ciencias Ambientales y Tercer Congreso de Medio Ambiente. Sus líneas actuales de investigación son: sustentabilidad de los sistemas rurales y urbanos. Entre sus publicaciones destacan: en coautoría, "Particularidades del huevo ranchero como producto de la ganadería familiar", en V. Cavalloti et al., Alternativas para el desarrollo sustentable de la agricultura. Respuesta de los productores y la perspectiva académica, Cedrssa-UACH-Colegio de Postgraduados, México, pp. 207-217 (2007); en coautoría, "Agricultura sustentable urbana y periurbana", en J. F. López Olguín et al., Avances en agroecología y ambiente, BuAP, Puebla, 
pp. 123-136 (2007); en coautoría, “De la seguridad a la soberanía alimentaria: una política pública para resolver el problema del hambre en México", en E. Reyes Altamirano y J. A. Paredes Sánchez, Seguridad alimentaria en Puebla: prioridad para el desarrollo, Colegio de Postgraduados-SDr-Gobierno del Estado de Puebla-Altres Costa-Mic, Puebla, pp. 46-61 (2008); en coautoría, "Ecología y tecnología en la producción agrícola: consideraciones desde el humanismo económico", en L. E. di Marco y A. Furlong y Zacaula, El humanismo económico: desde México hasta Argentina, CIEC-BuAp, Puebla, pp. 526-532 (2008).

Néstor Gabriel Estrella-Chulím. Es Ph. D. por el Departamento de Agronomía de la Universidad de Iowa, Estados Unidos. Es profesor-investigador adjunto en el Colegio de Postgraduados, Campus Puebla. Sus líneas actuales de investigación son: el enfoque territorial para promover el desarrollo agrícola y rural, y la caracterización y remediación de suelos contaminados por el derrame de hidrocarburos. Además de los aproximadamente 30 artículos científicos, capítulos de libros y libros que se reportan en el cvu del Conacyt y que sustentan la solicitud al sNI, ha participado como autor, coautor y compilador de 120 publicaciones que incluyen informes y folletos técnicos, folletos de divulgación, informes internos y memorias de congresos. Es miembro del Consejo Editorial de la Revista Saberes Compartidos, y de la Revista de Divulgación Cientifica, Tecnológica y Humanistica del Consejo de Ciencia y Tecnología del Estado de Puebla. Es integrante del Foro Consultivo Poblano de Ciencia y Tecnología, 1986-2008. Durante este periodo recibió diversos reconocimientos institucionales entre los que resaltan: como integrante del Premio de los 100 Académicos con Mayor Productividad del Colegio de Postgraduados y las becas al desempeño académico (Kados), 2006. Reconocimiento del Colegio de Ingenieros Agrónomos y de la Confederación Nacional Agronómica por labor destacada en el desarrollo rural, en febrero 2006. Reconocimiento de la Sagarpa, Productores Agropecuarios y la Red Nacional de Desarrollo Rural Sustentable, por el apoyo a la Red en noviembre de 1999, Montecillo, Estado de México, 2002. Es Premio Estatal de Ciencia y Tecnología en el Área de Biotecnología y Ciencias Agropecuarias, otorgado por el Gobierno del Estado de Puebla y el Consejo Estatal de Ciencia y Tecnología, noviembre de 2002, Puebla.

Jorge Luis Morett-Sánchez. Es doctor en agroecología, campesinado e historia por la Universidad de Córdoba, España. Es profesor-investigador de tiempo completo en el Departamento de Sociología Rural de la Universidad Autónoma Chapingo. Asimismo ha sido secretario de la Asociación Civil para Estudios Agrarios Ricardo Flores Magón; en la UACH se 
ha desempeñado como coordinador del Área de Metodología e Investigación, director del Departamento de Sociología Rural, secretario técnico académico, subdirector académico del Departamento de Sociología Rural. Ha sido consejero universitario, consejero departamental y consejero del posgrado de sociología rural. Sus líneas actuales de investigación son: problemática socioeconómica de la agroindustria cańera-azucarera; obreros agrícolas y migración; estudios sobre empresas asociativas en el campo, cooperativas, ejidos colectivos; estudios sobre globalización, transnacionales y agricultura. 